\title{
ARTIGO TEMÁTICO
}

\section{PRECARIZAÇÃO DO TRABALHO DO CIRURGIÃO-DENTISTA NA CIDADE DE SALVADOR, BAHIA}

Lana Bleicher

\section{Resumo}

O trabalho do cirurgião-dentista tem se tornado cada vez mais heterogêneo, embora a prática liberal ainda seja significativa, tanto em termos numéricos quanto no plano simbólico. Esta pesquisa tem o objetivo de desvendar em que medida a prática dos dentistas em Salvador é atingida pelos diferentes tipos de precarização do trabalho e compreender como estes profissionais percebem este processo. Trata-se de pesquisa qualitativa cujo instrumento de coleta de dados foi a entrevista semiestruturada aplicada a dentistas que mantinham ao menos uma inserção em Salvador. A pesquisa revelou que a tradição de profissão liberal impacta fortemente na subjetividade dos dentistas, fazendo-os perceber de forma naturalizada o ocultamento da condição assalariada e a falta de garantia de direitos trabalhistas. Embora associem determinadas enfermidades à prática odontológica, há uma tendência a percebê-las como inevitáveis. Todavia, há um discreto aumento da organização coletiva. Concluiu-se que a permanência da prática liberal como modelo idealizado de inserção no mercado de trabalho é funcional ao desenvolvimento de formas precarizadas de assalariamento.

Palavras-Chave: Administração da prática odontológica. Emprego. Dentista. Trabalho.

\section{PRECARIOUS WORK AMONG ORAL SURGEONS IN SALVADOR, BAHIA (BRAZIL)}

\footnotetext{
Abstract

The work of an oral surgeon has become increasingly heterogeneous, although the liberal practice is still significant, both quantitatively and symbolically. This research aims to demonstrate the extent to which the practice of dentists in Salvador is affected by different

a Doutora em Ciências Sociais. Professora da Faculdade de Odontologia da Universidade Federal de Odontologia, Universidade Federal da Bahia (UFBA).

Endereço para correspondência: Faculdade de Odontologia da UFBA. Rua Araújo Pinho n. ${ }^{\circ}$ 62, Canela, Salvador, Bahia. CEP: 41110-150. lanableicher@gmail.com
} 
Revista Baiana de Saúde Pública types of precarious work and understand how these professionals perceive this process. This is a qualitative research whose instrument of data collection was a semi-structured interview conducted with dentists who maintained at least one insertion in Salvador. The study showed that the tradition of independent profession impacts strongly in the subjectivity of the dentists, making them perceive naturally, the concealment of the wage-earning condition and the lack guarantee of labor rights. Although certain diseases are associated with dentistry practice, there is a trend to perceive them as inevitable. However, there is a slight increase of the collective organization. It can be concluded from this study that the persistence of the liberal practice as an idealized model of insertion in the labor market is functional to the development of precarious forms of wage labor.

Key words: Dental practice management. Dentist. Job. Work.

\section{PRECARIZACIÓN DEL TRABAJO DEL CIRUJANO-DENTISTA EN LA CIUDAD DE SALVADOR, BAHÍA}

\section{Resumen}

El trabajo del cirujano-dentista se ha hecho cada vez más heterogéneo, a pesar de que la práctica liberal sigue siendo significativa, tanto términos numéricos como simbólicos. Esta investigación tiene como objetivo develar, en qué medida la práctica de los dentistas en Salvador se ve afectada por los diferentes tipos de precariedad laboral y comprender como estos profesionales perciben este proceso. Investigación cualitativa, cuyo instrumento de recolecta de datos fue la entrevista semiestructurada, aplicada a los dentistas que mantenían, por lo menos, una inserción en Salvador. La investigación reveló que la tradición del profesión liberal impacta fuertemente en la subjetividad de los dentistas, llevándolos a percibir como algo natural el ocultamiento de la condición de asalariado y la falta de garantía de derechos laborales. Aunque asocien determinadas enfermedades a la práctica odontológica, hay una tendencia a percibirlas como inevitables. Sin embargo, hay un discreto crecimiento de la organización colectiva. Se concluye que la permanencia de la práctica liberal, como modelo idealizado de inserción en el mercado de trabajo, es funcional al desarrollo de precarias formas de trabajo asalariado.

Palabras-Clave: Administración de la práctica odontológica. Empleo. Dentista. Trabajo. 


\section{INTRODUÇÃO}

As últimas três décadas têm trazido profundas transformações no mercado de trabalho odontológico. O número de dentistas aumentou de 60 mil em 1980 para 220 mil em 2010.1,2 A última década foi marcada pela ampliação de postos de trabalho para dentistas no Sistema Único de Saúde (SUS), mas também pela expansão da Odontologia Suplementar. De 2001 a 2012, o número de Equipes de Saúde Bucal (ESB) no Programa de Saúde da Família (PSF) aumentou de 2.248 para 20.424. ${ }^{3}$ Entre 2000 e 2010, o número de beneficiários de planos exclusivamente odontológicos aumentou de 2.761.608 para $14.669 .586 .^{4}$

O mercado de trabalho dos dentistas torna-se, então, mais heterogêneo. A prática liberal ainda é significativa, tanto em termos numéricos quanto - principalmente - no plano simbólico. Não ocorreu seu desaparecimento, mas nota-se a coexistência entre essa prática e formas variadas de assalariamento, quer sejam típicas ou disfarçadas. O desenvolvimento da Odontologia Suplementar questiona a autonomia dos dentistas. ${ }^{5}$

Esta pesquisa justifica-se frente à escassez de estudos sobre a ocorrência da precarização do trabalho entre dentistas em um período em que este fenômeno atinge uma variedade cada vez maior de profissões. Tem por objetivo desvendar em que medida a prática dos dentistas em Salvador é atingida pelos diferentes tipos de precarização do trabalho e compreender como estes profissionais percebem este processo.

\section{REVISÃO DE LITERATURA}

Precarização e flexibilização são conceitos que tendem a figurar juntos. Insegurança e instabilidade: essas são as ideias mais comumente associadas ao termo "flexibilização". Estudo ${ }^{6}$ salienta que este processo, que deriva de nova fase de mundialização do sistema capitalista, expressa-se em jornadas móveis de trabalho, salários flexíveis e formas de gestão inspiradas no toyotismo. Este é o motivo pelo qual flexibilização e precarização são conceitos que costumam ser associados. Estudo ${ }^{6}$ sobre terceirização entende que a precarização é constituída pela expansão e institucionalização da insegurança e atinge o conjunto dos trabalhadores. Estudos demonstram como o processo de precarização do trabalho pode atingir também profissionais que tradicionalmente gozam de prestígio, como médicos ${ }^{7}$ e dentistas ortodontistas. ${ }^{8}$ Os efeitos da precarização são sentidos por qualquer homem ou mulher, sob a forma de incerteza perante o futuro. Tal incerteza mina a possibilidade de uma revolta coletiva contra o presente. Assim, mesmo os que não são atingidos diretamente pela precariedade sofrem seus efeitos ideológicos, pois o emprego passa 
Revista Baiana de Saúde Pública a ser visto como um frágil privilégio a ser perdido caso articule uma resposta de classe: "A insegurança objetiva funda uma insegurança subjetiva". 9:121

\section{MATERIAL E MÉTODOS}

Fez-se a opção pela metodologia qualitativa. Foram realizadas entrevistas semiestruturadas com 14 dentistas que tivessem pelo menos uma inserção como dentista na cidade de Salvador, Bahia. Foi utilizado um roteiro de entrevista semiestruturado que abordou as condições de trabalho dos entrevistados, como transitam entre os polos de autonomia e heteronomia no trabalho, suas percepções em relação ao assalariamento e precarização, quais as soluções vislumbradas, suas trajetórias e formações, dentre outras questões. Para garantir a diversidade de situações necessárias ao estudo, a amostra abrangeu dentistas de diferentes gerações, homens e mulheres, incluindo pessoas que se encontravam ou já tinham vivenciado as seguintes situações: assalariamento no setor público e privado (com e sem vínculo empregatício); trabalho por porcentagem; trabalho por aluguel de turnos; atendimento a planos de saúde em consultório próprio e na empresa contratante; prática liberal; credenciamento a planos odontológicos e proprietário de empresa na condição de empregador. As entrevistas foram realizadas entre julho de 2010 e abril de 2011. Os primeiros entrevistados foram incluídos após os contatos realizados na assembleia de dentistas e indicações de dentistas conhecidos pela pesquisadora, à semelhança do método empregado em pesquisa qualitativa em saúde. ${ }^{10}$ Em seguida, foram acessados sujeitos indicados pelos entrevistados iniciais.

Quanto aos procedimentos de análise, foram seguidas as proposições de estudo sobre o uso do grupo focal em pesquisa qualitativa: ${ }^{11}$ leitura exaustiva dos depoimentos; indexação (ordenação e categorização) dos dados; agrupamento das categorias por afinidade, compondo temas descritores; submissão dos temas descritores a uma análise específica, releitura das categorias e construção de subtemas; interpretação dos dados à luz do referencial teórico.

Foi assegurado o anonimato e o direito de recusa aos participantes da pesquisa. Neste trabalho, os depoentes estão identificados pela palavra Dentista, seguida do número que correspondeu a cada depoimento, da seguinte forma: Dentista 1, Dentista 2.... Dentista 14. O projeto desta pesquisa foi submetido ao Sistema Nacional de Informações Sobre Ética em Pesquisa envolvendo Seres Humanos, registrado com o Certificado de Apresentação para Apreciação Ética (CAAE) de número 0031.0.368.000-09, tendo sido aprovado no dia 13 de outubro de 2009. 


\section{RESULTADOS E DISCUSSÃO}

A articulação entre o debate conceitual da precarização social do trabalho e sua expressão empírica torna-se mais clara ao se empregar a tipologia proposta em artigo sobre trabalho, precarização e resistências, ${ }^{12}$ que norteará a apresentação dos achados da pesquisa.

\section{DIREITOS TRABALHISTAS}

Um primeiro tipo de precarização social do trabalho aponta para a heterogeneidade do mercado de trabalho, mediante formas de inserção precárias, vulneráveis e desprotegidas. ${ }^{12}$ A ocorrência deste primeiro tipo resultou em farto material empírico.

Ainda que o trabalho precário sempre tenha existido no Brasil, há um fenômeno de conteúdo novo. ${ }^{6}$ No caso dos dentistas, a inovação faz-se acompanhar do peso de uma tradição: a prática liberal. Na história desta profissão, a autonomia esteve acompanhada de prestígio social e retorno financeiro. A flexibilidade da prática liberal tinha uma conotação positiva. Conforme foi se dando o assalariamento, ocorreu a perda da autonomia e uma piora dos rendimentos, mas a flexibilidade não desapareceu.

Os direitos à aposentadoria, férias, licença maternidade não são referências para o dentista autônomo. O dentista liberal não vende sua força de trabalho, mas a emprega para si. Assim, precisa zelar por sua capacidade laboral, mas está isolado neste cuidado. As saídas encontradas para as situações de velhice, doença, maternidade e descanso são entendidas como decisão de foro íntimo: pagar ou não contribuição como autônomo ao Instituto Nacional do Seguro Social (INSS)? Fazer ou não um plano de previdência privada? Tirar ou não férias? Após o parto, voltar a trabalhar com 15 ou 45 dias? São questões que não envolvem um empregador, dizem respeito, supostamente, apenas ao fato de ser mais ou menos previdente.

É com o padrão da prática liberal que os dentistas precarizados procuram paralelos, não com o trabalhador assalariado típico. Isto ajuda a explicar certa naturalidade com que a ausência de direitos trabalhistas é encarada. Espera-se do dentista que trabalha em situação de assalariamento disfarçado que contribua "como autônomo" ao INSS da mesma forma que um dentista liberal típico. Recai sobre o indivíduo a responsabilidade: se está descoberto, é ele o imprevidente, não o empregador que descumpre a legislação. Em alguns trechos das entrevistas, aparece essa autorresponsabilização, representada na fala do jovem Dentista 11, que não contribui para o INSS e afirma: "Vai deixando, deixando, deixando e vou eu mesmo me prejudicando pro futuro." (grifo nosso).

Os dentistas autônomos, em geral, estavam protegidos, seja pelo sistema público de aposentadoria, seja por seguros privados. A fala do Dentista 3, formado na década de 
Revista Baiana de Saúde Pública
1990, também reforça a responsabilização dos indivíduos quanto a ausência de cobertura previdenciária: "Na cabeça dos [...] jovens dentistas não está claro, entendeu? Porque o pessoal acha que, como antigamente, você faria o patrimônio e esse patrimônio seria sua aposentadoria." Perceba-se, neste trecho, o reforço à ideia de uma negligência dos jovens dentistas com seu próprio futuro.

Quando perguntadas sobre o direito à licença maternidade, as dentistas com vínculo empregatício no setor público referiram ter usufruído este direito. Contudo, as que exerciam a prática liberal afirmaram ter retornado ao trabalho pouco tempo após o parto:

"Quando eu tive minha filha, quinze dias depois, eu tava trabalhando [riso]. Voltei a trabalhar junto com ela [...] Eu tinha consultório [...] eram duas salas. Uma [ficava ela]. Até três meses eu fazia isso, trabalhava e amamentava. Amamentava a cada três horas. Com três meses, ela... aí já não tinha condição de ficar, mas é uma das coisas que eu me culpo, porque devia ficar pelo menos um mês em casa, eu não tive." (Dentista 8).

Tanto nesta entrevista como em outras, aparece a necessidade de apressar o retorno ao trabalho porque, exercendo a prática liberal, a interrupção do atendimento significava a suspensão de ganhos. Ao falar "eu me culpo", a dentista toma para si a responsabilidade pelo acontecimento.

Há uma nebulosidade em torno da questão da precarização dos vínculos e como é percebida pelos dentistas no setor privado. Poder-se-ia agrupar essas situações precárias em dois grandes grupos: um com ausência total de contratualização; outro com contratos que buscam esconder a condição de assalariado.

O primeiro é bastante comum nos casos do trabalho em clínicas de porcentagem. Denomina-se trabalho por porcentagem aquele em que o dentista desloca-se para o consultório pertencente a outro (seja ou não um dentista), despendendo apenas uma pequena parte dos insumos necessários à produção. Via de regra, as instalações, equipamentos e instrumentais pertencem ao dono da clínica e o equipamento de proteção individual (gorro, máscara, luva) e micromotor, ao dentista, mas há outras configurações menos comuns. A cobrança ao paciente ou à operadora de plano em geral cabe ao dono da clínica, que repassa ao dentista entre 40 a 50\% do valor obtido. Parece que, por haver certa proximidade à prática liberal, mesmo que seja na aparência, não ocorre o estranhamento em relação à ausência de direitos trabalhistas. É comum haver relações de amizade com o 
dono da clínica. Se este não frauda os valores a pagar, se cumpre o acordo verbal firmado, se mantém condições satisfatórias de trabalho (como atendimento às normas de biossegurança), a situação não é vista como injusta. Ao descrever a prática generalizada de falta de formalização de contrato em que trabalham os dentistas, a Dentista 8 afirma "É informal. É acreditando que ninguém vai acionar juridicamente."

Um segundo grupo de dentistas que se assalariam no setor privado deve ser mencionado: os que constituem pessoa jurídica (PJ) para trabalhar em empresa, a que denominamos "pejotizados". Aqui o limite entre o assalariamento disfarçado e a autonomia é ainda mais tênue. A fala da Dentista 4 é bastante representativa de como o trabalho "pejotizado" é visto pelos dentistas em contraste com a condição do liberal:

"Se o consultório [particular] não produz, você tem um monte de conta pra pagar. Hoje [...] se eu não produzo lá [na empresa em que é "pejotizada"], o máximo que eu tenho pra pagar é o contador e mesmo assim dividido. Se eu não recebo, eu também não onero." (Dentista 4).

É sintomático que a entrevistada elenque as vantagens do trabalho como "pejotizado" em relação à prática liberal e não com a situação de um trabalhador protegido pelas normas trabalhistas, que não apenas não seria onerado, mas continuaria a contar com rendimentos. As queixas feitas em relação ao formato de pessoa jurídica foram em relação aos impostos e gastos com contador, que são descontentamentos frequentes entre dentistas liberais.

Quando questionados sobre férias, tanto os dentistas liberais quanto os que trabalham em porcentagem afirmaram que, em geral, não gozavam um mês inteiro de ausência do trabalho. Assim, para o dentista liberal, a existência de períodos de menor movimento no consultório, devido a feriados, representa a possibilidade de usufruir um tempo de lazer com a família. Para o dentista que trabalha em percentagem como assalariado disfarçado, este vazio na agenda significa menos uma oportunidade de lazer que um momento de vulnerabilidade: "Eu nunca tive férias, entendeu? Eu tenho vinte e nove anos, tenho cinco anos de formado e, infelizmente, eu não sei o que é férias nem o que é décimo terceiro. Pra mim tudo isso é tão bonito, tão distante, não vejo a possibilidade de eu ter isso um dia." (Dentista 11, grifo nosso).

Na visão do entrevistado, a ideia do trabalho em porcentagem aparece como uma derivação da prática liberal, não como uma precarização do trabalho assalariado. Há, no senso comum, a ideia de que o profissional liberal é seu próprio patrão e determina seu processo 
Revista Baiana de Saúde Pública de trabalho, sua jornada, seu tempo de lazer. Uma flexibilidade que se contrapõe à rigidez do assalariamento típico, com horários a cumprir, prescrições a seguir. Os achados desta pesquisa sugerem que, para os dentistas que trabalham no sistema de percentagem, a flexibilidade é muito mais de rendimentos do que uma autonomia na organização do trabalho.

\section{INSEGURANÇA E RENDA}

A metodologia utilizada não permite fazer inferências sobre a renda dos dentistas em Salvador, mas aponta indícios de que os jovens dentistas recebem pior remuneração que os profissionais formados há mais tempo. Para os jovens, a inserção no setor privado, trabalhando em clínicas de porcentagem, representa insegurança, como ilustra a fala da Dentista 1, formada há menos de três anos: "Você não sabe exatamente o que você vai ter disponível pra você no final do mês, né. Que antes, quando eu trabalhava na unidade básica, tinha um salário fixo, e agora você não tem."

A associação do trabalho em porcentagem à imprevisibilidade e vulnerabilidade está presente tanto na fala da Dentista 1 quanto dos Dentistas 11 e 13, também formados há menos de dez anos. Tanto a Dentista 1 quanto o Dentista 11 declararam preferir o assalariamento no setor público ao trabalho em porcentagem. Mesmo quando este assalariamento não era tão próximo do padrão, ainda que contratados no serviço público como prestadores de serviço, sem garantias de estabilidade, a preferência recai sobre o emprego público.

A precarização social do trabalho calca-se no desemprego ou ameaça deste, produzindo isolamento, perda de identidade e contingentes de supranumerários. ${ }^{12}$ Entre os participantes da pesquisa, não identificamos a ocorrência expressiva de desemprego aberto: há muitos postos de trabalho, mas muitos são de baixa qualidade. A marca presente no segundo tipo de precarização social do trabalho é a insegurança, que leva à perda de enraizamento, à descartabilidade e à desvalorização. ${ }^{12} \mathrm{~A}$ insegurança mais relatada pelos dentistas refere-se à oscilação de rendimentos: "Todo mundo [colegas formados no mesmo período] na mesma situação, empacado, trabalhando em clínica por porcentagem, reclamando da instabilidade, dos planos de saúde odontológicos diminuindo a tabela, atrasando o pagamento, sabe?" (Dentista 13).

Dentistas de gerações anteriores, como os Dentistas 5 (formada nos anos 1980) e 6 (formado nos anos 1960), relatam ter sentido insegurança no passado, o que os motivou a buscar o assalariamento no setor público. Alcançaram este objetivo, tornando-se servidores estatutários. Mas, em seu discurso, essa tática não assume a centralidade que o tema ocupa na 
fala dos dentistas mais jovens. Salienta-se que, mesmo o assalariamento no setor público, tão almejado pelos jovens dentistas, não afasta completamente a insegurança. São relatados casos de demissão imotivada (uma vez que eram prestadores de serviço) e atrasos no pagamento do salário pelo período de três meses.

A insegurança está intimamente relacionada à questão dos rendimentos. Este é um assunto particularmente difícil no estudo de dentistas. Há, no imaginário - tanto da sociedade quanto dos dentistas -, a crença de que, em um passado de três ou quatro décadas, a Odontologia permitia enriquecer. O cenário que se apresenta aos jovens dentistas hoje é diverso. Como exemplo, cita-se a Dentista 1, que trabalha em percentagem para outros dentistas, atendendo planos de baixa remuneração em quatro clínicas diferentes de distintos bairros. Não tem carteira assinada, direito a férias ou décimo terceiro salário e aufere por mês R\$ 1.500 reais no máximo. Este valor sofre grandes oscilações sazonais, o que lhe dá uma sensação de insegurança muito intensa.

A metodologia utilizada nesta pesquisa revela mais quanto às percepções dos dentistas sobre sua renda do que sobre a renda propriamente dita. Reconhece-se que há a possibilidade de os entrevistados referirem um passado idealizado, que uma memória seletiva tenha retido somente determinados aspectos mais positivos dos períodos anteriores. Há, na fala dos três dentistas formados nos anos 1980, a ideia de um período áureo, de fortes possibilidades de crescimento profissional. O trecho a seguir é ilustrativo:

“Naquela época, assim, quando eu decidi fazer Odontologia, era a profissão que estava no auge. Então, o mercado de trabalho completamente aberto [...] quase todo mundo já tinha, assim, o consultório montado ou a montar logo, pelo menos no primeiro ano de curso. E assim, e com clientela já segura." (Dentista 2).

Os Dentistas 2, 5 e 12 afirmam que não apenas a autonomia típica era mais promissora que nos dias atuais, mas também havia melhor remuneração no credenciamento a planos odontológicos e mesmo o trabalho em porcentagem aparecia como vantajoso, pois, com melhores rendimentos, possibilitava a transição à autonomia típica. Somente era valorado negativamente o emprego público.

A geração de 1990 foi lançada no mercado ainda tendo por referencial a geração que a precedeu: "O dentista não é mais aquele profissional rico, não é? Então acho que muita gente apostava que, na Odontologia, eles seriam ricos; não é mais." (Dentista 8). Este é o período relatado como a entrada em Salvador dos planos odontológicos mais massificados - as 
Revista Baiana de Saúde Pública operadoras de Odontologia de Grupo que atualmente predominam no mercado. A geração formada nos anos 2000 já está bem distanciada do cenário promissor dos anos 1980.

Nas entrevistas, o relato de melhora de rendimentos apareceu apenas no setor público, ilustrado na fala da Dentista 5: "[desde] que eu comecei a trabalhar, o único remunerado bom assim, de mercado de trabalho, na parte pública, foi o PSF." O emprego público da Dentista 5 difere daqueles dos Dentistas 1 e 11, por ter rendimentos bastante superiores, garantia de direitos trabalhistas e por atuar na mesma cidade em que reside.

\section{PROCESSO DE TRABALHO E CONDIÇÕES DE VIDA}

Os padrões de gestão e organização do trabalho dão origem a um terceiro tipo de precarização, concorrendo para a intensificação do trabalho. ${ }^{12}$ Entre dentistas, fenômenos como a extensa jornada de trabalho e a perda da autonomia podem ser tomados como indicadores. O aumento da jornada, a intensificação da produtividade, a ocorrência de doenças relacionadas ao trabalho articulam-se também com aspectos da vida fora do trabalho: o tempo de lazer e o convívio com a família. As condições de trabalho parecem estar relacionadas à questão da autonomia no processo de trabalho. A jornada e intensidade de trabalho, provavelmente, têm significados distintos quando percebidos por sujeitos que governam seus próprios atos ou por aqueles que se encontram subordinados.

Embora o número de entrevistados não permita fazer inferências, suspeita-se que a jornada de trabalho extensa pode ter sido comum mesmo na época de ouro da Odontologia. O Dentista 12, formado nos anos 1980, iniciou-se na profissão conjugando emprego público e consultório próprio: "Eu ia até 10 da noite, todo dia". É enfático: "Então, assim, eu sempre trabalhei muito". Todavia, este profissional pôde, com o tempo, reduzir sua jornada de trabalho: "Só atendo dois pacientes pela manhã e dois pela tarde". A Dentista 2, da mesma geração, endossa: "Eu me lembro que [...] trabalhava muito assim à noite; a gente trabalhava às vezes até as duas da manhã, três da manhã." E também diminuiu a carga de trabalho com o tempo.

Não se tem como afirmar até que ponto tais relatos são representativos desse período, mas, certamente, revelam bastante sobre concepções de trabalho. Note-se que a extensa jornada de trabalho é valorizada. A agenda cheia denota não apenas o quão dedicado é o profissional: atesta também seu sucesso. Nossa pesquisa não autoriza afirmar que as novas gerações de dentistas passaram a trabalhar mais ou menos horas por semana, mas permite supor que o significado deste trabalho tenha se transformado. Se, por um lado, a Dentista 1, 
na época da realização da entrevista, trabalhava somente quatro dias na semana, por outro, os Dentistas 11 e 13 relataram jornadas bastante prolongadas. Mas o trabalhar muito não é referido pela Dentista 13 com o mesmo orgulho que o Dentista 12. Alternando trabalho em porcentagem entre Salvador e um município da região metropolitana, a jovem dentista afirma: "Mas eu espero, com a graça de Deus, que eu venha largar o sábado, porque eu estou cansada. Eu chego em Salvador três horas da tarde [do sábado], que é que eu faço mais? Eu durmo, eu não tenho mais vida social."

Um ponto que gostaríamos de salientar refere-se à noção de flexibilidade. Tradicionalmente, a prática liberal é associada de forma positiva à flexibilidade de horários - essa seria uma vantagem de "ser o próprio patrão". Embora este conteúdo apareça desta forma na fala da Dentista 7 , encontrou-se também a flexibilidade com outro sentido: quando se perguntou à Dentista 8 quantos turnos na semana tinha ocupados, respondeu "todos", incluindo sábado e domingo. Explicando melhor seu dia a dia, ela diferenciou os turnos fixos dos turnos em que fica à disposição da clínica, para o caso de haver paciente: "Eu sei que quarta-feira à noite, previsto para estar lá [clínica de terceiros], então não marco em nenhum outro local. Porque eu tenho assim: horários que eu sei que estou em determinado lugar,

pode ser que eu não tenha paciente. É um risco meu. Eu corro esse risco. Mas geralmente tem." (Dentista 8).

Note-se que o risco da não existência de paciente é imputado ao trabalhador: ela não deve assumir compromisso com outro trabalho no horário estipulado, mas não havendo paciente, não é remunerada. Há um dispositivo ideológico bastante eficiente em ocultar os conflitos de classe que consiste em um mimetismo da prática assalariada atípica em liberal.

\section{ADOECER NO TRABALHO}

Um quarto tipo de precarização social do trabalho diz respeito à falta de segurança e saúde no trabalho. ${ }^{12}$ Há uma articulação estreita ao item anterior, uma vez que os processos de trabalho muitas vezes afetam negativamente a saúde dos dentistas.

A existência de doenças relacionadas ao trabalho do dentista não é uma novidade na literatura. A análise de obras didáticas tradicionais ${ }^{13}$ sobre prevenção dos riscos ocupacionais da prática odontológica é interessante por dois motivos. O primeiro: as orientações dos autores para prevenir os riscos ocupacionais têm como destinatário o profissional liberal. O dentista é orientado como deve planejar e organizar o seu consultório para evitar tais doenças. Em segundo lugar, percebe-se que o processo de produção de doenças narrado é apartado da vida social e suas causas são naturalizadas. 
Revista Baiana de Saúde Pública elementos importantes para estimular pesquisas posteriores. Além das doenças tradicionalmente reconhecidas como bastante prevalentes entre dentistas, relacionadas a fatores ergonômicos, percebe-se também problemas referentes ao sofrimento psíquico. Tal condição não é exclusiva das gerações mais novas ou das situações mais precarizadas, mas, no contexto da entrevista, percebeu-se que a intensidade do sofrimento era maior entre esses.

Aparentemente, os riscos ocupacionais, tais como problemas de coluna, tendinite, entre outros, são democráticos entre dentistas e podem acometer tanto autônomos extremamente bem localizados no mercado quanto assalariados precarizados. Mas não se pode ocultar que ser capaz de definir o próprio ritmo de trabalho coloca o problema em outro patamar. No enfoque tradicional dos riscos ocupacionais da prática odontológica, ${ }^{13}$ caberia ao dentista liberal ser sensato o suficiente para seguir as prescrições e preservar sua capacidade de trabalho. O Dentista 12, ao atender somente dois pacientes por turno, provavelmente está bem menos exposto a adquirir doenças profissionais, mesmo tendo quase trinta anos de formado e exercer uma especialidade mais propensa a doenças do trabalho. Há uma flagrante diferença em relação à Dentista 13 que, em seus poucos anos de formada, já percebe deterioração de sua saúde. Como não relacionar seu adoecimento à sua condição de assalariamento disfarçado, a uma rotina semanal que só termina às quinze horas do sábado?

\section{ORGANIZAÇÃO SINDICAL}

Os obstáculos à organização social dos trabalhadores integram o quinto tipo de precarização social do trabalho. ${ }^{12}$ Existe uma dificuldade já histórica dos dentistas em fazer uso de formas de luta coletiva, todavia contrapostas a promissoras novidades. Há uma carência de tradição de organização sindical entre dentistas. Não se encontraram artigos sobre o assunto na literatura e, nas declarações dos dentistas em blogs e comunidades virtuais, é predominante o argumento de que dentistas nunca se unem. Há a percepção de que sempre foi assim; esta não seria uma característica do momento atual do mercado de trabalho e sua explicação estaria na característica liberal da profissão? A tradicional incapacidade de organização dos dentistas é vista como fruto do isolamento não apenas físico, mas também do fato de, na prática liberal, os sujeitos se entenderem como concorrentes.

Todavia, enquanto estava sendo realizada a fase de campo desta pesquisa, teve curso uma paralisação da categoria odontológica em reação à diminuição dos valores pagos por uma empresa de planos odontológicos. ${ }^{14} \mathrm{O}$ acompanhamento de assembleia, das entrevistas e a leitura dos informativos das entidades odontológicas possibilitaram perceber-se 
uma razoável capacidade de divulgação, mobilização e negociação, que culminou com o atendimento do pleito. Embora os ganhos obtidos com a paralisação não tenham perdurado por muito tempo e mesmo persistindo problemas com outras operadoras de planos, o exemplo aponta a possibilidade de maior organização coletiva dos dentistas.

\section{CONSIDERAÇÕES FINAIS}

Esta pesquisa auxilia na compreensão do processo de precarização social do trabalho ao focar as condições de trabalho de um segmento muito específico da classe-que-vive-do-trabalho. Um elemento importante para justificar a assertiva de que a tradição liberal facilita a naturalização do assalariamento precário é o tema dos direitos trabalhistas. A ideologia do empreendedorismo joga para cada trabalhador a responsabilidade por seu sucesso e bem-estar individual. Não foi necessário convencer os dentistas desta assertiva, pois já a tomam como fundamento da prática liberal. Férias, afastamento do trabalho para se recuperar de uma enfermidade ou após o parto, manutenção de renda na velhice, todos esses elementos são entendidos como de ordem privada: cabe ao dentista, na condição de "patrão de si mesmo", tomar providências para que possa garanti-las.

Em um cenário de ganhos satisfatórios e plena autonomia no processo de trabalho, isto não representava um problema. Todavia, a situação muda quando surge o comprador da força de trabalho, que passa a limitar a autonomia e se apropriar de parcela da riqueza produzida.

A autonomia sobre o processo de trabalho encontra-se diminuída, como pode ser percebido no caso dos dentistas que atendem em seus próprios consultórios, mas são conveniados a planos. A empresa não precisa, necessariamente, ter o processo produtivo sob seu teto e o dentista tem certa liberdade para definir seu processo de trabalho, desde que não ultrapasse as balizas estabelecidas pelas regras contratuais e o valor remunerado. Todavia, a aparência é de que a escolha cabe ao profissional.

Se, por um lado, pôde-se perceber uma inserção do dentista no mercado de forma mais desprotegida, por outro, há alguns indícios de crescimento da organização coletiva. Talvez as condições concretas a que estão submetidos os odontólogos estejam sendo capazes de furar dois bloqueios: a tradicional dificuldade de ação sindical dos dentistas e o momento particularmente difícil por que passa o movimento sindical mais geral. São elementos ainda bastante incipientes para serem apresentados como tendência, mas que podem vir a colocar o conflito capital-trabalho que existe no interior da Odontologia de mercado em um novo patamar. 
Revista Baiana

de Saúde Pública

\section{AGRADECIMENTOS}

À Professora Dra. Graça Druck, orientadora da tese que originou esta publicação.

\section{REFERÊNCIAS}

1. Pinto VG. Saúde bucal no Brasil. Rev Saúde Pública. 1983;17(4):316-27.

2. Conselho Federal de Odontologia. Dados estatísticos. Brasília; 2010. Extraído de: [http://cfo.org.br/servicos-e-consultas/Dados-estatisticos/?elem ento $=$ profissionais\&categoria $=C D \& c r o=$ Todos\&municipio $=]$, acesso em $[1$ de fevereiro de 2010].

3. Brasil. Ministério da Saúde. Os números. Brasília; 2011. Extraído de: [http://dab. saude.gov.br/abnumeros.php\#numeros], acesso em [23 de agosto de 2011].

4. Brasil. Ministério da Saúde. Agência Nacional de Saúde. Caderno de informação da saúde suplementar: beneficiários, operadoras e planos. Brasília; 2011. Extraído de: [http://www.ans.gov.br/portal/site/informacoesss/ informacoesss.asp], acesso em [24 de agosto de 2011].

5. Freitas CHSM. Dilemas no exercício profissional da Odontologia: a autonomia em questão. Interface. 2007;11(21):25-38.

6. Thébaud-Mony A, Druck G. Terceirização: a erosão dos direitos nos trabalhadores na França e no Brasil. In: Druck G, Franco T. A perda da razão social do trabalho: terceirização e precarização. São Paulo: Boitempo; 2007. p. 23-58.

7. Nascimento Sobrinho CL, Carvalho FM, Nascimento MA. Transformações na organização do trabalho médico no Brasil. Rev Baiana Saúde Pública. 2004;28(1):78-90.

8. Bassani JCB. Trabalho e reconhecimento: análise das condições de trabalho e reconhecimento na clínica odontológica X, em Porto Alegre, em 2009. Conversas e Controvérsias. 2010;1(1):40-56.

9. Bourdieu P. Contrafogos: táticas para enfrentar a invasão neoliberal. Rio de Janeiro: Zahar; 1998. p. 121.

10. Schraiber LB. Pesquisa qualitativa em saúde: reflexões metodológicas do relato oral e produção de narrativas em estudo sobre a profissão médica. Rev Saúde Pública. 1995;29(1):63-74.

11. Ressel LB, Beck CLC, Gualda DMR, Hoffmann IC, Silva RM, Sehnem GD. $\mathrm{O}$ uso do grupo focal em pesquisa qualitativa. Texto contexto - enferm. 2008;17(4):779-86.

12. Druck G. Trabalho, precarização e resistências: novos e velhos desafios? Cad CRH. 2011;24:37-57. 
13. Saquy PC, Pécora JD. Orientação profissional em Odontologia. São Paulo: Santos; 1996.

14. Conselho Regional de Odontologia da Bahia. CDs vencem batalha contra Convênio Odontológico. J Croba. 2010;17;78:3.

Recebido em 15.11.2012 e aprovado em 21.11.2012. 